\title{
Peer-Delivered Cognitive Behavioral Training and Reduced Pain
}

\author{
Michael E Jobansen, MD, MS, Associate Editor, Annals of Family Medicine; Alexandra Blood, MD; \\ and Juliana Boateng, DO, Grant Family Medicine, Columbus, Obio \\ Ann Fam Med 2020;18(1):iii. https://doi.org/10.1370/afm.2514.
}

The Annals of Family Medicine encourages readers to develop a learning community to improve health care and health through enhanced primary care. Participate by conducting a RADICAL journal club. RADICAL stands for Read, Ask, Discuss, Inquire, Collaborate, Act, and Learn. We encourage diverse participants to think critically about important issues affecting primary care and act on those discussions. ${ }^{1}$

\section{HOW IT WORKS}

In each issue, the Annals selects an article and provides discussion tips and questions. Take a RADICAL approach to these materials and post a summary of your conversation in our online discussion. (Open the article and click on "TRACK Discussion/ Submit a comment.") Discussion questions and information are online at: http://www.annfammed.org/site/AJC/.

\section{CURRENT SELECTION}

\section{Article for Discussion}

Andreae SJ, Andreae LJ, Richman JS, Cherrington AL, Safford MM. Peer-delivered cognitive behavioral training to improve functioning in patients with diabetes: a cluster-randomized trial. Ann Fam Med. 2020;18(1):15-23.

\section{Discussion Tips}

Chronic pain is difficult to treat, especially in the setting of chronic conditions. Clinically, we struggle with this in primary care as we rarely have adequate resources or time to help these patients deal with these problems. This clustered randomized controlled trial offers some insight into how we might be able to better help these patients through cognitive behavioral therapy delivered by trained community health workers. We'd recommend spending some time investigating the recruitment and enrollment of this trial as the patient population is one that is rarely enrolled in clinical trials.

\section{Discussion Questions}

- What question is asked by this study and why does it matter?
-What is a cluster-randomized controlled trial? How is this different from "traditional" randomized controlled trials? Why do the authors control for clustering? What are the strengths and weaknesses of cluster randomization?

- Define chain referral sampling. What are the strengths and weaknesses of this method?

- How does this study advance beyond previous research and clinical practice on this topic?

- What was the comparator intervention? Do you think this a valid comparison?

- To what degree can the findings be accounted for by: o How patients were selected, excluded, or lost to follow-up? How is the recruitment different from the majority of clinical trials?

o How and when the main variables were measured?

o Confounding (false attribution of causality because 2 variables discovered to be associated actually are associated with a 3rd factor)? o Chance? o How the findings were interpreted?

-What are the main study findings? Do you expect to see changes in hemoglobin $\mathrm{A}_{1 \mathrm{c}}$ or blood pressure?

-What is social desirability bias? Could this have affected the results? Did the researcher enlist methods to decrease this possibility? Could they have used others?

- How comparable is the study sample to similar patients in your practice? What is unique about this study population?

-What contextual factors are important for interpreting the findings?

- How might this study change your practice? Policy? Education? Research?

-What researchable questions remain?

\section{References}

1. Stange KC, Miller WL, McLellan LA, et al. Annals Journal Club: It's time to get RADICAL. Ann Fam Med. 2006;4(3):196-197. http:// AnnFamMed.org/cgi/content/full/4/3/196. 